CORRECTION

https://doi.org/10.1038/s41586-019-1208-1

\title{
Publisher Correction: Electron magnetic reconnection without ion coupling in Earth's turbulent magnetosheath
}

T. D. Phan, J. P. Eastwood, M. A. Shay, J. F. Drake,

B. U. Ö. Sonnerup, M. Fujimoto, P. A. Cassak, M. Øieroset, J. L. Burch, R. B. Torbert, A. C. Rager, J. C. Dorelli,

D. J. Gershman, C. Pollock, P. S. Pyakurel, C. C. Haggerty,

Y. Khotyaintsev, B. Lavraud, Y. Saito, M. Oka, R. E. Ergun,

A. Retino, O. Le Contel, M. R. Argall, B. L. Giles, T. E. Moore,

F. D. Wilder, R. J. Strangeway, C. T. Russell, P. A. Lindqvist \&

W. Magnes

Correction to: Nature https://www.nature.com/articles/s41586-0180091-5, published online 09 May 2018.

In Fig. $3 \mathrm{f}$ of this Letter, owing to an error in the production process, the $y$-axis values are incorrect, and should go from 4 to -8 (rather than from 4 to -4$)$, and in Fig. $3 \mathrm{~h}$, the $y$-axis values $(18,20,22,24)$ should appear next to the major tick marks (rather than the minor ticks). In addition, in Fig. 1b, the arrows at the top and the bottom of the electron-scale current sheet were going in the wrong direction. These errors have been corrected online. 